\title{
Alternative Measures of Noncognitive Skills and Their Effect on Retirement Preparation and Financial Capability
}

Gema Zamarro

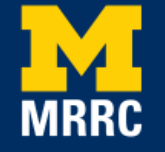

Project \#: UM17-12 


\title{
Alternative Measures of Noncognitive Skills and Their Effect on Retirement Preparation and Financial Capability
}

\author{
Gema Zamarro \\ University of Arkansas \& University of Southern California
}

September 2017

\author{
Michigan Retirement Research Center \\ University of Michigan \\ P.O. Box 1248 \\ Ann Arbor, MI 48104 \\ www.mrrc.isr.umich.edu
}

(734) 615-0422

\section{Acknowledgements}

The research reported herein was performed pursuant to a grant from the U.S. Social Security Administration (SSA) funded as part of the Retirement Research Consortium through the University of Michigan Retirement Research Center Award RRC08098401-09. The opinions and conclusions expressed are solely those of the author(s) and do not represent the opinions or policy of SSA or any agency of the federal government. Neither the United States government nor any agency thereof, nor any of their employees, makes any warranty, express or implied, or assumes any legal liability or responsibility for the accuracy, completeness, or usefulness of the contents of this report. Reference herein to any specific commercial product, process or service by trade name, trademark, manufacturer, or otherwise does not necessarily constitute or imply endorsement, recommendation or favoring by the United States government or any agency thereof.

Regents of the University of Michigan

Michael J. Behm, Grand Blanc; Mark J. Bernstein, Ann Arbor; Shauna Ryder Diggs, Grosse Pointe; Denise Ilitch, Bingham Farms; Andrea Fischer Newman, Ann Arbor; Andrew C. Richner, Grosse Pointe Park; Ron Weiser, Ann Arbor; Katherine E. White, Ann Arbor; Mark S. Schlissel, ex officio 


\title{
Alternative Measures of Noncognitive Skills and Their Effect on Retirement Preparation and Financial Capability
}

\begin{abstract}
Social science, more than ever, is drawing upon the insights of personality psychology. Though researchers now know that noncognitive skills and personality traits, such as conscientiousness, grit, self-control, or a growth mindset could be important for life outcomes, they struggle to find reliable measures of these skills. Self-reports are often used for analysis, but these measures have been found to be affected by important biases. We study the validity of innovative, more robust measures of noncognitive skills based on performance tasks. Our first proposed measure is an adaptation, for the adult population, of the Academic Diligence Task (ADT) developed and validated among students by Galla et al. (2014). For our second type of performance task measures of noncognitive skills, we argue that questionnaires themselves can be seen as performance tasks, such that measures of survey effort, e.g. item non-response rates and degree of carelessness in answering, could lead to meaningful measures of noncognitive skills. New measures along with self-reports are then used to study the role of noncognitive skills and personality traits on an individual's preparation for retirement and financial capability. In a world where individuals are increasingly asked to take responsibility for retirement preparations and when available financial products to do so are growing in sophistication, a better understanding of how noncognitive skills influence retirement preparation could help effective policy design.
\end{abstract}

\section{Citation}

Zamarro, Gema. 2017. “Alternative Measures of Noncognitive Skills and Their Effect on Retirement Preparation and Financial Capability.” Ann Arbor MI: University of Michigan Retirement Research Center (MRRC) Working Paper, WP 2017-365.

http://mrrc.isr.umich.edu/wp365/

\section{Author's acknowledgements}

Special thanks to Angela Duckworth and Arie Kapteyn for their feedback and support for this project. I also thank conference participants at the 2017 University of Michigan Retirement Research Center (MRRC) Research Workshop for all of their comments. 


\section{Introduction}

Retirement preparation is lacking among adults. There are concerns that most people do not accumulate enough retirement savings and end up lacking resources during the retirement years (Poterba, 1996). In addition, an increasing share of the responsibility for a good financial situation and a good financial plan for the future is given to individuals and less to governments. This, in addition to a growing level of sophistication of financial products, leads to the necessity for a better understanding of the personal factors that drive some individuals and not others to make sound financial decisions and better prepare for retirement. A better understanding of these factors is crucial for the design of effective policies and interventions that could help promote financial capability and retirement preparation.

Noncognitive skills and personality traits, such as grit, self-control, a growth mindset, and conscientiousness, could be important factors driving individual differences in financial capability and retirement preparation. These noncognitive skills have been found to play a prominent role in shaping long-term outcomes, such as educational attainment and labor outcomes, beyond the role of cognitive ability (Almlund et al., 2011). However, we still lack a good understanding of how they affect policy relevant outcomes, such as preparation for retirement and financial capability.

A limited amount of recent research has highlighted the potential role that personality traits could have for retirement planning and savings. Hershey and Mowen (2000), using a small sample of Arkansas households, studied the link between personality characteristics, financial knowledge, and financial preparedness. They found that both personality characteristics, such as conscientiousness and neuroticism as well as financial knowledge, were significantly correlated with retirement planning. Hurd et al. (2012) also highlights the role of, in particular, 
conscientiousness for retirement preparation. Using data from the Health and Retirement Study the authors find conscientiousness to be associated with a higher accumulation of resources for retirement both through an increased level of earnings but also through higher levels of saving. Finally, in a recent paper, Parise and Peijnenburg (2017) study the relationship between conscientiousness and emotional stability (reverse of neuroticism) and financial choices among a panel of Dutch adults. They find that both personality traits are negatively associated with several measures of financial distress. Also, these personality traits were associated with higher levels of retirement planning and saving and negatively associated with impulse buying and unsecured borrowing. We build on this research and: 1) Further study the validity of innovative more robust measures of noncognitive skills based on performance tasks; and 2) Study the effect of different measures of noncognitive skills to explain individuals’ preparation for retirement and financial capability.

Finding robust measures of noncognitive skills and personality traits can be challenging. Previous research has used only self-reported measures of noncognitive skills, but these can have limitations as they are prone to potential biases. To date, three approaches have been proposed for obtaining measures of noncognitive skills: 1) measures based on self-reports; 2) measures based on real-life outcomes such as student's grades, absences, credits earned, disciplinary infractions, etc.; and 3) measures derived from performance tasks, where respondents are asked to perform a specific, carefully designed task to detect meaningful differences in behaviors as indicative of their level of a given skill. None of the approaches for measuring noncognitive skills has proven fully reliable, and not all of these measures are widely available for research purposes. In particular, measures based on real-life outcomes are seldom available for researchers. As a result, most researchers who aim to assess the potential impacts of 
noncognitive skills have relied on self-reports for their measurement. However, self-reports of noncognitive skills have been found to be affected by reference group bias and social desirability bias (Dobbie and Fryer, 2015; Krosnick, Narayan, and Smith, 1996; West et al., 2016). Also, some respondents expend low effort on surveys. The problem this creates for noncognitive skills research is that effort on surveys is likely related to the very skills that researchers are attempting to measure. For example, respondents who lack grit or self-control are unlikely to report that they lack those skills. This indicates that measurement error on surveys is potentially related to the underlying skills we seek to measure, which then could lead to invalid research findings.

Though performance-task measures do not always suffer the same sources of biases as previously described measures, they have limitations of their own. First, tasks can be costly and difficult to administer in large samples. Second, it is not always clear that artificial tasks completed in a lab setting are generalizable to other contexts. Also, the ability of behavioral tasks to capture the noncognitive skills of interest is not always clear (Bardsley, 2008; Duckworth and Yeager, 2015; Falk and Heckman, 2009; Levitt and List, 2007). Finally, existing performance tasks are difficult to implement multiple times, as participants might show learning effects after having performed the task once.

Because of these limitations, Duckworth and Yeager (2015) have urged the research community to exercise caution when using existing self-reported measures of noncognitive skills for evaluation purposes. The authors highlight the importance of developing novel measures by capitalizing on advances in theory and technology. This is precisely what we do in this paper, i.e. study the validity of promising innovative performance task-based measures.

In this paper we study the validity of two types of performance tasks to capture noncognitive skills among adults in the Understanding America Study (UAS), an internet panel 
of households. First, we study an adaptation, for the adult population, of the Academic Diligence Task (ADT) developed and validated among high school students by Galla et al. (2014). Secondly, we argue that questionnaires themselves can be seen as performance tasks, such that measures of survey effort can lead to meaningful measures of noncognitive skills. Our results show the difficulty of adapting the ADT to a different context and population and the promise of survey effort measures to proxy for relevant noncognitive skills. In particular, measures of careless answering in surveys show great promise for being good proxy measures of conscientiousness and neuroticism. When related with measures of financial capability and retirement preparation, we find that both self-reported measures of conscientiousness, neuroticism, and grit as well as careless-answering behaviors are important determinants of the level of financial capability of UAS respondents. These results highlight the importance of considering psychological factors in the design of policies to aim to improve the level of financial capability and retirement preparation in the population.

The rest of the paper is structured as follows. Section 2 describes the data and alternative measures of noncognitive skills used in our analysis. Section 3 describes our empirical approach for studying the effect of alterative measures of noncognitive skills on retirement preparation and financial capability. Section 4 describes the results, while Section 5 discusses final conclusions and further research plans.

\section{Data}

This project uses the UAS, an ongoing internet panel of American households run by the University of Southern California, comprising a nationally-representative sample of 
approximately 6,000 respondents. ${ }^{1}$ Once or twice a month, UAS respondents complete surveys that last up to 30 minutes each. Since all data can be linked across waves, a large amount of information about each respondent is available longitudinally, including demographic information, work status, education, financial literacy, cognitive capabilities, and personality traits (e.g., Big Five Inventory, John and Srivastava, 1999). Respondents also complete the Health and Retirement Study questionnaire, which contains detailed information of work history, income, assets, health, and retirement preparation and savings. Furthermore, this project builds on work in Zamarro et al. (2016) for which a wave of data that included self-reported grit (Duckworth and Quinn, 2009) was collected. Also available in the UAS are paradata, which include detailed information on whether a respondent skipped a question he or she should have answered. These paradata are used to build measures of survey effort and to evaluate performance in the diligence task.

\subsection{Self-reported Measures of Noncognitive skills}

Self-reported measures of noncognitive skills used in this study include measures of the Big Five personality traits as well as self-reported grit measures. The Big Five is a taxonomy of five universal and major personality traits including: conscientiousness, agreeableness, neuroticism (also known conversely as emotional stability), extraversion, and openness. Overall, the Big Five model is one of the most widely used schemas in personality research and practice. More recently, economists also have been using this model and found that each of the Big Five personality traits affect life outcomes in a variety of ways (Almlund et al., 2011; Borghans et al., 2008).

\footnotetext{
${ }^{1}$ It is important to note that participants are not limited to households who have computer hardware or purchase internet access. The UAS research team provides internet access and hardware, such as tablets, so that all households in the sample may participate. For more information about the UAS, visit: https://uasdata.usc.edu/
} 
Our measures of the Big Five personality traits were collected in the very first survey UAS respondents take after joining the panel (UAS 1). It is based on a 44-item scale developed by John, Donahue, and Kentle (1991). Based on the answers to this scale, each respondent receives a continuous score from one to five on each of the five personality dimensions described above.

Grit is defined as “perseverance and passion for long-term goals” (Duckworth et al. (2007), p. 1087). We collected self-reported measures of grit through the grit scale developed and validated by Duckworth and Quinn (2009). This is an eight-item scale where respondents are asked to evaluate themselves on a five-point scale (Very much like me; Mostly like me; Somewhat like me; Not much like me; Not like me at all) on a series of statements including, among others, “I am a hard worker,” “I am diligent,” and “Setbacks don’t discourage me.” A grit score is then computed for each respondent to the survey by averaging the scores from responses to each of the eight items in the scale. Duckworth and Quinn (2009) validated this grit scale in a series of convenience samples, including a sample of adults aged 25 and older. In this particular sample, they found that self-reported grit measures presented (a) a strong, positive correlation with self-reported measures of conscientiousness ( $\rho=0.77$ ); (b) a moderate, negative correlation with self-reported neuroticism $(\rho=-0.40)$; (c) weak, positive correlations with agreeableness $(\rho$ $=0.24)$ and extraversion $(\rho=0.20)$; and $(d)$ a very weak correlation with openness to experience $(\rho=0.06)$

Tables 1 and 2 present descriptive statistics for these self-reported measures of personality traits and grit collected in the UAS. Similarly to validation results in Duckworth and Quinn (2009), self-reported grit measures in our sample exhibit strong, significantly positive correlations with self-reported measures of conscientiousness, a moderate significantly negative 
correlation with self-reported neuroticism, a moderate significantly positive correlation with agreeableness, and a weak significant positive correlation with extraversion and openness to experience. Observed correlations, however, are generally of smaller size, with the exception of openness to experience, than those observed by Duckworth and Quinn (2009) for a sample of adults. This could be due to differences in sample composition, as we use a nationally representative, address-based recruited sample and their work used a convenience sample of volunteers to participate in the study. We also observe some intercorrelations among the Big Five personality traits measures in this table. For instance, conscientiousness exhibits positive, moderate correlation with agreeableness and negative, moderate correlation with neuroticism. These intercorrelations are to be expected as certain behaviors, used for their measure, may reflect multiple traits. For instance, "interpersonal warmth is found to be related to both extraversion and agreeableness,” and are not unusual in the personality literature (Costa and McCrae, 1992, p. 862).

\subsection{Alternative Measures of Noncognitive skills}

\section{The Academic Diligence Task}

The Diligence Task or the Academic Diligence Task (ADT) is a computer-generated task first validated among high school students by Galla et al. (2014). In the original task, students were given the option to perform simple math problems, which they were told to be beneficial for them, or play computer games. This task was designed to measure academic diligence by mirroring a real-world choice that students face when completing homework: the choice to remain engaged in tedious, but important assignments, and/or browse the internet or play video games. Tested in a convenience sample of high school seniors, Galla et al. (2014) found that the number of questions answered correctly (i.e. productivity) and the time spent on task were 
weakly but significantly correlated with self-reported conscientiousness $(\rho r=0.08$ and 0.09$)$ and grit $(\rho r=0.16$ and 0.17$)$. Additionally, productivity and the time on task were also significantly correlated with high school GPA, academic achievement, on-time high school graduation, and college enrollment.

We adapted the ADT and collected data on a subsample of UAS respondents. First, respondents were prompted about the importance of simple mental exercises and their potential role on preventing cognitive diseases (e.g. Alzheimer's disease). Secondly, they were asked to choose five Web pages from a list of 23 that would be available during the task, our distractors. Finally, respondents were asked to perform as many verbal and math problems as possible in 10 minutes, but allowed to take breaks to surf the Web on their five selected Web pages available to them during the task. Figure 1 shows screenshots of the task as it was performed in the UAS.

Tables 1 and 2 present descriptive statistics of the percentage of correct responses among the total of questions answered by respondents, as well as the percentage of total time they were on task. Similarly, Figures 2 and 3 describe the distribution of these variables in our sample. As can be seen in these figures, the big majority of respondents did not seem to be tempted by our distractors; they took the task very seriously and devoted all or almost all their time to perform the task. This lead to very high percentages of questions correct during the task. This behavior resulted in a lack of variation across respondents on their performance in the task leading to very small correlations with self-reported, noncognitive skills as seen in Table 2. The percentage of correct answers was only very weakly correlated with self-reported grit and conscientiousness in our sample ( $\rho r=0.04$ and 0.03 ). The percentage of time on task was only weakly positively correlated with self-reported conscientiousness $(\rho r=0.05)$ and in fact, appeared weakly negatively correlated with self-reported grit measures ( $\rho r=-0.06)$. Given the low construct 
validity of the ADT in our sample, as seen from these small correlations, we do not think this would be a meaningful measure of relevant noncognitive skills in this case. As it turns out, we also found no correlation between ADT performance and financial capability or retirement preparation in our sample. ${ }^{2}$

Measures of Survey Effort

For our second type of performance-task measures of noncognitive skills, we argue that questionnaires themselves can be seen as performance tasks, such that measures of survey effort can lead to meaningful measures of noncognitive skills. Surveys take effort to complete and respondents reveal something about their noncognitive skills through the effort they exhibit on them.

Survey effort can be measured by analyzing response patterns within surveys. Recent evidence has highlighted the potential of studying response patterns to questionnaires and tests as a way of quantifying noncognitive skills (see Hitt, 2015; Hitt, Trivitt, and Cheng, 2016; Zamarro, Mendez, and Hitt, 2016). For example, the rate at which students skip questions on surveys is predictive of later educational attainment and labor-market outcomes (Hitt, Trivitt, and Cheng, 2016). Similarly, measures of "careless answering” on surveys by both teen-age students and adults based on the extent to which respondents tend to deviate from predicted responses to questions, within validated scales, given their and others' responses to the rest of questions in the scale, are found to be predictive of educational and labor-market outcomes in adulthood (see Hitt, 2015; Zamarro et al., 2016).

By quantifying the extent to which individuals put effort in surveys, we are able to obtain information about respondents who otherwise may provide unreliable, self-reported information. In addition, these performance and task-based measures are not prone to reference group bias as

\footnotetext{
${ }^{2}$ Results available from the authors upon request.
} 
respondents simply reveal personal attributes by their behavior. Also, respondents are typically unaware that they are being assessed on survey effort, which avoids issues such as social desirability bias or experimenter bias. An added cost-effective benefit of survey-based effort measures is that these measures often will not require new data to be collected. Therefore, one could obtain measures of noncognitive skills from existing surveys to complement the alreadycollected information in these surveys, expanding the opportunity for researchers to answer new questions with existing data. In this study, we follow the work by Zamarro et al. (2016) and study the potential of measures of item nonresponse and careless answering in the UAS to proxy for relevant noncognitive skills.

Item nonresponse rates are defined as the percentage of items that respondents skipped out of the total number of items they were required to complete in a given survey. We compute the item nonresponse rates for surveys in ten different waves of data in the $\mathrm{UAS}^{3}$ that all respondents were asked to participate in and that were particularly long and so presented more potential for observing patterns of item nonresponse. These survey waves were fielded at different points of time and varied in topics including demographic and family background information, health status and knowledge, housing, income, employment and labor market, retirement, pensions, social networks, and opinion on economics and politics. Altogether, respondents were asked an average of 93.3 questions in each of these ten survey waves. We then take the average item nonresponse rate across waves and within each respondent. By averaging nonresponse rates along multiple surveys covering different topics, we aim to identify a

\footnotetext{
${ }^{3}$ The UAS survey waves included in this measure were the following: UAS16, UAS18, UAS20, UAS21, UAS22, UAS23, UAS24, UAS25, UAS26 and UAS38.
} 
behavioral pattern independent of a specific survey topic and less affected by random fluctuations. ${ }^{4}$

Tables 1 and 2 present summary statistics for item nonresponse measures as well as correlations with other measures of noncognitive skills. On average, UAS respondents exhibited item nonresponse rates of about 8 percent. Similarly to the results presented for the ADT above, item nonresponse rates, however, did not present much construct validity in our sample as they showed very weak correlations with our self-reported measures of grit and personality traits. Although weak, correlations were, however, significant and in the expected direction. Weak negative and significant correlations were observed with self-reported grit, conscientiousness, agreeableness and openness to experience. A marginally significant, positive weak correlation was also observed with self-reported neuroticism. These small correlations could be due to the fact that item nonresponse is discouraged in the UAS. If respondents leave an answer blank, this triggers a screen that reminds them of the importance of their answers and asks them to return and provide a response. ${ }^{5}$ As a consequence, we have doubts that item nonresponse is a good proxy for noncognitive skills in this case. However, in the results section below, we will still present our results of correlations between item nonresponse rates and financial capability and retirement preparation in our sample.

Careless Answering Measures: Instead of skipping items, some respondents may provide thoughtless and incoherent answers. For instance, some respondents may report the same answer to every question (i.e., straight-lining) in order to quickly complete the survey with minimal

\footnotetext{
${ }^{4}$ Computing item nonresponse from a set of surveys also addresses the potential issue that this behavior might be driven not by lack of effort but by the sensitivity of questions. Prior research has found that respondents tend to skip items that are sensitive in nature (Tourangeau and Yan, 2007). By averaging item nonresponse over a set of survey waves covering a range of topics, we mitigate the possibility that the measure is driven by one survey containing several sensitive questions.

${ }^{5}$ Obviously, respondents can choose to ignore the alert and continue answering subsequent items, hence the nonzero item nonresponse rates
} 
effort (O’Conner, Sullivan, and Jones, 1982). Others may simply provide random answers. Our second measure of survey effort identifies these patterns. In particular, we aim to measure the extent to which a respondent is carelessly submitting answers to surveys.

As described in Zamarro et al. (2016), we follow Hitt (2015) to build a measure of careless answering by generalizing diagnostic techniques that psychologists have used to analyze data quality (Huang et al., 2012; Johnson, 2005; Meade and Craig, 2012). First, we identify reliable self-reported scales that respondents had to answer. We study answer patterns in several survey waves, fielded at different points in time and covering an array of topics. We restrict our analysis to survey waves different from the waves that contain other data for our analysis to eliminate confounding variation. We chose the following three scales to build our careless answering measure: a life satisfaction scale, a well-being scale, and a depression scale. ${ }^{6}$ All these scales in our data had high reliability coefficients, ranging from 0.7 to 0.9 Cronbach's alpha scores.

Within each of the selected scales, we regress responses from each item on the average score of the rest of items. Answers among items in a reliable scale should be well correlated with each other. However, an individual who is careless in responding to a scale will submit answers that are more weakly correlated with each other. Residuals from each of our regressions will capture the response inconsistencies between each item and the remaining items, based upon the responses that the individual and others in the analytic sample provided on those remaining items.

We standardize the absolute values of these residuals to account for any differences across the items within the same scale and then average these standardized residuals within

\footnotetext{
${ }^{6}$ The life satisfaction and the well-being scales are from UAS2. The depression scale is in UAS20.
} 
scales. Finally, after standardizing each of these averages to take into account differences across scales (e.g., different total number of items, or answer options), we create a composite careless answering score by averaging these standardized averages of residuals at the individual level ${ }^{7}$. Using this same type of measure, Hitt (2015) has shown that adolescents who engage in this type of behavior to a larger degree have lower levels of educational attainment in adulthood, controlling for cognitive ability and demographic factors. He suggests this behavior is reflective of conscientiousness. Using a slightly different set of scales, Zamarro et al. (2016) showed that careless answering in the UAS was a good proxy for conscientiousness and neuroticism and that it was related to final levels of education and labor outcomes, even after controlling for a rich set of demographic and cognitive ability measures.

Tables 1 and 2 show summary statistics for careless answering measures in our sample, as well as correlations with other measures of noncognitive skills. Careless answering is a standardized measure and so the mean and standard deviation are not so informative. However, we observe a significant range in values of careless answering behavior with some respondents giving well predicted answers (negative values) and others presenting higher unexpected responses (positive values). As was also the case in results presented in Zamarro et al. (2016), we find that careless answering in our sample is most correlated with self-reported measures of neuroticism (positively correlated) and with self-reported measures of conscientiousness and grit (negatively correlated). This result speaks to the construct validity of careless answering. In the next section, we will explore its relationship with financial capability and retirement preparation, along with the self-reported measures of grit and personality traits.

\footnotetext{
${ }^{7}$ See Hitt (2015) for additional technical details and explanation on this measure of careless answering.
} 


\subsection{Retirement Preparation and Financial Capability Measures}

Our analysis uses three sets of outcome measures with the aim to capture different dimensions of respondents’ financial capability, consumer financial well-being, and retirement preparation. As part of our measures of financial capability, we include respondent's financial literacy scores based on respondent's responses to 20 questions developed to measure their financial knowledge. Respondents then get scored on a scale of one to 20 representing the number of questions they answered correctly. In that same survey, right after the financial test questions, respondents were also asked to self-report how many questions out of the 20 questions presented they think they have answered correctly, from 0 to 20. This measure constitutes our perceived financial literacy scale. ${ }^{8}$ Finally, we include information about respondent's total value of assets, excluding the value of secondary residence, ${ }^{9}$ measured in 10,000 s of dollars, as another measure of financial capability.

Consumer financial well-being, defined by the Consumer Financial Protection Bureau (CFPB) as the level to which a person can fully meet current and ongoing financial obligations, can feel secure in their financial future, and is able to make choices that allow them to enjoy life, is captured through the CFPB financial well-being scale. ${ }^{10}$ The scale is based on a set of 10 questions and a specific scoring system by which a financial well-being score on a scale of 0 to 100 is provided, with higher scores representing higher levels of financial well-being. ${ }^{11}$ In addition, we also use information on respondents' reported credit scores and generated an indicator variable for the respondent reporting a good or excellent credit score (above 700$){ }^{12}$

\footnotetext{
${ }^{8}$ The financial literacy score and perceived financial literacy measures were collected as part of UAS6.

${ }^{9}$ This variable is obtained from the UAS HRS public use dataset.

${ }^{10}$ This variable is obtained from UAS38.

${ }^{11}$ For more information see: https://www.consumerfinance.gov/data-research/research-reports/financial-well-beingtechnical-report/

${ }^{12}$ Information on credit scores is obtained from UAS 48.
} 
Our final set of outcome variables aims to capture respondents' reported levels of preparation for retirement. In particular, we developed two indicator variables that capture if the respondent reported being very well or somewhat prepared financially for retirement and whether the respondent has thought and developed a plan for retirement through answering yes to both of the following questions: "In the past, have you ever tried to figure out how much your household should save for retirement?” and "Have you ever tried to develop a plan for your retirement?"13

Table 3 presents summary statistics for our outcome variables. Out of 20 financial literacy questions, on average, UAS respondents responded correctly to almost 14 questions while they perceived they had responded correctly to 13 of such questions. On average, respondents report about $\$ 287,000$ in total value of assets. On a scale from 0 to 100 , the average of consumer well-being in our sample is about 54 points. Forty-nine percent of respondents report having good or excellent credit scores, 22 percent report being financially prepared for retirement ,while only 13 percent report having thought about and tried to develop a retirement plan.

\subsection{Cognitive Ability and Other Relevant Information}

There are multiple sources of information on cognitive ability in the UAS that we use in this analysis. These include the Lipkus Numeracy Scale (Lipkus et al., 2001), responses to a Cognitive Reflection Test (Frederick, 2005; Toplak et al., 2014), and a quantitative reasoning, picture vocabulary, and verbal analogies battery from the Woodcock-Johnson Tests of Cognitive Abilities (Mather and Jaffe, 2016). We combined information on all these scales to form a

\footnotetext{
${ }^{13}$ Information to build these two indicator variables was obtained from UAS16 and UAS26.
} 
unique cognitive ability index using factor analysis of the total number of correct responses in each of these tests. All scales loaded onto a unique factor with relative, equal-size weights. ${ }^{14,15}$

Other relevant demographic controls included in our analysis include information about respondent's age, gender, ethnicity, whether born in the U.S, region of residence (West, Midwest, Northeast, or South), whether the respondent is currently working, whether the respondent is currently retired, education level (college degree, high school degree), and whether the respondent is currently married or living together with a partner.

Table 4 presents summary statistics for demographic variables and our cognitive ability measure included in the analysis. On average, our respondents are about 47 years old, a majority are working (61 percent), have a high school degree (50 percent) or a college degree (40 percent) and are born in the U.S. (91 percent). Half of the sample is male and half female.

\section{Empirical Approach for Studying the Effect of Noncognitive skills on Retirement Preparation and Financial Capability}

We next study the role of both self-reported measures of noncognitive skills and measures of item nonresponse and careless answering, as behavioral, task-based measures that proxy for conscientiousness and neuroticism, on explaining financial capability and retirement preparation. We estimate slight variations of the following linear regression model:

$$
\mathrm{Y}=\beta_{0}+\beta_{1} X_{i}+\beta_{2} \text { Non_cognitive skills }{ }_{i}+\gamma_{i}^{S}+\varepsilon_{i}(1)
$$

Where $Y$ is an outcome measure, as described in section 2.3 above. $\beta_{2}$ is the coefficient of interest representing the association between respondents’ noncognitive skills and retirement preparedness. Our regressions include the following alterative measures of noncognitive skills:

\footnotetext{
${ }^{14}$ Information on the Lipkus Numeracy Scale and Cognitive Reflection Test were collected during the very first survey of the UAS (UAS 1), while the quantitative reasoning, picture vocabulary, and verbal analogies battery from the Woodcock-Johnson Tests of Cognitive Abilities where collected during later waves in UAS 42, 43 and 44.

${ }^{15}$ Results are available from the authors upon request.
} 
self-reported Big Five personality traits, self-reported grit measures, item nonresponse rates and measures of careless answering. Four sets of separate regressions are obtained including each of these four alternative measures of different noncognitive skills. $X_{i}$ includes relevant socioeconomic background information, education level, cognitive ability, work status, and marital status, as described in section 2.4. Finally, we also control for regional dummies collected in $\gamma_{i}^{S}$ as a means of controlling for any unobserved differences across regions in the U.S.

\section{Results}

Tables 5.A and 5.B present regression coefficients for the effect of noncognitive skills on financial literacy scores, perceived financial literacy, and total value of assets, according to specification (1). All regressions control for respondent's demographic information, educational attainment levels, employment, marital status, and cognitive ability. Columns 1, 3, and 5 of Table 5.A. present the estimated effect of each of the self-reported Big Five personality traits. As can be seen, we fail to find a statistically significant effect of self-reported conscientiousness on financial literacy scores or total value of assets. From the Big Five personality traits, only openness to experience shows a small but statistically significant effect on financial literacy scores. A one-point increase in openness is associated with about a 0.2-point increase in the financial literacy score. Interestingly, all self-reported personality traits except for openness to experience are significantly associated with perceived levels of financial literacy. Conscientiousness and extraversion are positively associated with perceived financial literacy levels, while agreeableness and neuroticism are negatively related. Columns 2, 4, and 6 of Table 5.A present the results when self-reported grit is included as an explanatory variable in the analysis instead of the Big Five personality traits. Similarly to the results we observed for self- 
reported conscientiousness, a personality trait found to be related to grit, we observe that selfreported grit does not show any statistically significant association with financial literacy scores or total value of asset measures. However, an increase of one point in self-reported grit is associated with a 0.4-point increase in perceived financial literacy scores. Table 5.B. presents the results for our survey effort measures. Columns 1, 3, and 5 present the results for measures of item nonresponse. In this case, we observe that a 1-percent increase in item nonresponse is associated with a 0.07 statistically significant decrease in financial literacy scores. A similar effect is found for perceived financial literacy levels, but this effect is not statistically significant. Surprisingly, we find that higher item nonresponse is associated with higher value of total assets. A 1-percent increase is associated with about a $\$ 16,000$ increase in assets. This result is contrary to what we expected if item nonresponse were to be a good proxy for noncognitive skills related to conscientiousness and neuroticism, and generates doubts about this measure being a good proxy for relevant noncognitive skills in this data. Finally, Columns 2, 4, and 6 of Table 5.B present the results when careless answering measures are used as performance-task measures of conscientiousness and neuroticism related skills. Interestingly in this case, we do observe small but statistically significant effects of careless answering behavior not only on self-reported financial literacy but also on actual financial literacy scores and total value of assets. A onestandard deviation increase in careless answering is associated with a 0.09 decrease in financial literacy scores, a 0.3 decrease in perceived financial literacy and a \$36,000 decrease in total value of assets. It should be stressed that these estimates are obtained after controlling for cognitive ability, educational levels, and other relevant sociodemographic information. Overall, in all regressions, cognitive ability seems to be a significant driver of financial capability and retirement preparation measures. 
Tables 6.A and 6.B present results when the CFPB financial well-being scale and an indicator variable for the respondent reporting good or excellent credit scores are used as dependent variables. Looking at Columns 1 and 3 of Table 6.A, we observe that conscientiousness is significantly associated with financial well-being levels as well as the probability of reporting good or excellent credit scores. An increase of one point in self-reported conscientiousness is associated with a 2.6 increase on the CFPB financial well-being scale and a 6-percentage point increase in the probability of reporting good or excellent credit scores. Neuroticism and extraversion are also found to be significantly associated with CFPB financial well-being levels. A one-point increase in reported neuroticism and extraversion is associated with a 2.4 decrease and a 0.6 increase in the financial well-being scale, respectively. Agreeableness and openness to experience, on the other hand, are found to be significantly correlated with the probability of reporting a good or excellent credit score. A one-point increase in agreeableness or openness is associated with a 3- and a 4-percentage points decrease in the probability of having a good or excellent credit score, respectively. Columns 2 and 4 of Table 6.A show the results of models that include self-reported grit as explanatory variable. In this case, we find that self-reported grit only shows a significant effect on the CFPB financial wellbeing index but not on the probability of reporting a good or excellent credit score. A one-point increase in self-reported grit is associated with an almost four-point increase in the financial well-being index. In contrast, as presented in Columns 2 and 4 of Table 6.B, careless answering is found to be correlated with both the financial well-being index and reporting having good or excellent credit scores. A standard deviation increase in careless answering is associated with an almost three-point decrease in financial well-being and a 5-percentage point decrease in the 
probability of reporting good credit. Item nonresponse rates were only weakly correlated with the financial well-being index, as can be seen in columns 1 and 3 of this table.

Results for regressions of self-reported retirement preparation are presented in Tables 7.A and 7.B. Looking at columns 1 and 3 of Table 7.A, we observe that, among the Big Five personality traits, both conscientiousness and extraversion are statistically significantly related to the probability of reporting having prepared for retirement and having developed a retirement plan. A one-point increase in the conscientiousness level is associated with an almost 6percentage point increase and a 3-percentage point increase in the probability of reporting having prepared for retirement and having developed a plan, respectively. The effect of extraversion is somewhat smaller. A one-point increase in the extraversion scale is associated with an almost 3percentage point increase in the probability of having prepared for retirement and a 1.5percentage point increase in the probability of having developed a plan. Agreeableness and neuroticism are also found to be correlated with reported retirement preparation, but their effect is negative. A one point increase in agreeableness and neuroticism is associated with a 3- and a 2-percentage point decrease in the probability of having prepared for retirement, respectively. Looking at Columns 2 and 4 of Table 7.A, we observe that self-reported grit is also significantly related to reported retirement preparation. A one-point increase in the grit scale is associated with a 3-percentage point increase in the probability of both having prepared for retirement and having developed a retirement plan. Careless answering is a behavior also found to be correlated with these outcomes as it can be seen in Columns 2 and 4 of Table 7.B. However, the correlation is found to be bigger for the probability of reporting having prepared for retirement than for the probability of actually having developed a plan. A one-standard deviation increase in careless answering behavior is associated with a 4.5-percentage point decrease in the probability of being 
prepared for retirement but only a 1.4-percentage point decrease in the probability of having thought of a retirement plan. Item nonresponse presented no association with retirement preparation variables.

\section{Conclusions}

As the population ages and individuals are increasingly responsible for making sound financial decisions for their future, understanding the factors that contribute to financial capability and retirement preparation becomes increasingly important. In this paper, we explore the potential role that noncognitive skills such as conscientiousness, neuroticism, and grit could have on promoting financial well-being and retirement preparation. Although previous research has highlighted the important role that these so called noncognitive skills have on shaping longterm outcomes, such as educational attainment and employment, beyond the role of cognitive ability, not much research has looked at their effect on financial outcomes. In addition, the little research available has focused on using self-reported measures of these noncognitive skills which could be problematic due to potential biases, including reference group bias and social desirability bias. Using data from the UAS, we further study the role of noncognitive skills on financial capability and retirement preparation, not only using self-reports but also exploring alternative measures of noncognitive skills based on performance tasks.

Our first proposed measure was an adaptation, for the adult population, of the Academic Diligence Task (ADT) developed and validated among high school students by Galla et al. (2014). Our results, however, show the difficulty of adapting the ADT to a different context and population. Most of respondents in the UAS that took the ADT did not seem to be tempted by the distractors offered during the task. They took the task very seriously and devoted all or almost all their time to perform the task. This resulted in very high percentages of correct 
answers during the task, a lack of variation across respondents on their performance, very small correlations with self-reported measures of noncognitive skills, and a lack of construct validity. Future research is needed to better design performance-task measures that could work in an internet panel for a similar population as represented in the UAS.

For our second set of performance task based measures, we explored survey effort measures on the idea that questionnaires themselves can be seen as tasks, such that measures of survey effort can lead to meaningful measures of noncognitive skills. One advantage of these measures is that respondents are typically unaware that they are being assessed on survey effort, which can help minimize experimenter effects on task performance. We studied measures based on item nonresponse rates and careless answering behaviors. Our results for item nonresponse rates show how the construct validity of these measures could be affected by survey design decisions. Item nonresponse is discouraged in the UAS. If respondents leave an answer blank, this triggers a screen that reminds them of the importance of their answers and asks them to return and provide a response. Since respondents know that, they may be tempted to provide a less than thoughtful answer rather than leaving a question unanswered. We believe this could have contributed to the finding that item nonresponse does not appear to be a good proxy for relevant noncognitive skills in the UAS. Item nonresponse rates showed very small correlations with self-reported measures of noncognitive skills, indicating a lack of construct validity for this measure. In contrast, measures of careless answering showed promise to be good proxy measures of noncognitive skills related to conscientiousness and neuroticism.

Finally, we explore the relationship between self-reported measures of noncognitive skills, item nonresponse rates and careless answering behavior and measures of financial capability, financial well-being, and retirement preparation. Our results show that both self- 
reported measures of noncognitive skills as well as careless-answering behaviors are important determinants of the level of financial capability and retirement preparation among UAS respondents. With the exception of financial literacy scores and total value of assets, selfreported conscientiousness was found to be significantly related to financial well-being and retirement preparation. Self-reported grit was also found to be significantly related to higher levels of financial well-being, perceived financial literacy levels, and retirement preparation and planning. Interestingly, careless answering consistently showed significant correlations with all outcome variables considered. Those respondents who engaged in this behavior also showed lower levels of financial literacy scores, perceived financial literacy, total value of assets, financial well-being scores, lower probability of reporting good or excellent credit scores and retirement preparation. These results highlight the importance of considering psychological factors when designing policies that aim to improve the level of financial capability and retirement preparation in the population. 


\section{References}

Almlund, M., Duckworth, A., Heckman, J., and Kautz, T. (2011). Personality psychology and economics. In E.A. Hanushek, S. Machin, and L. Wossmann (Eds.), Handbook of the Economics of Education (pp. 1-181). Amsterdam: Elsevier.

Bardsley, N. (2008). Dictator game giving: Altruism or artefact?. Experimental Economics, 11(2), 122-133.

Costa, P. T. Jr., and McCrae, R. R. (1992). Revised NEO Personality Inventory (NEO-PI-R) and NEO Five-Factor Inventory (NEO-FFI) Professional Manual. Odessa, Florida: Psychological Assessment Resources, Inc.

Dobbie, W., and Fryer, R. G. (2015). The medium-term impacts of high-achieving charter schools. Journal of Political Economy, 123(5), 985-1037.

Duckworth, A. L., Peterson, C. Matthews, M. D., and Kelly, D. R. (2007). Grit: Perseverance and passion for long-term goals. Journal of Personality and Social Psychology, 92(6), 1087-101.

Duckworth, A. L., and Quinn, P. D. (2009). Development and validation of the Short Grit Scale (GRIT-S). Journal of Personality Assessment, 91(2), 166-174.

Duckworth, A. L., and Yeager, D. S. (2015). Measurement matters assessing personal qualities other than cognitive ability for educational purposes. Educational Researcher, 44(4), 237-251.

Falk, A., and Heckman, J. J. (2009). Lab experiments are a major source of knowledge in the social sciences. Science, 326(5952), 535-538.

Frederick, S. (2005). Cognitive reflection and decision making. The Journal of Economic Perspectives, 19(4), 25-42.

Galla, B. M., Plummer, B. D., White, R. E., Meketon, D., D'Mello, S. K., and Duckworth, A. L. 
(2014). The Academic Diligence Task (ADT): Assessing individual differences in effort on tedious but important schoolwork. Contemporary Educational Psychology, 39(4), 314325.

Grant, H. and Dweck, C.S. (2003). Clarifying achievement goals and their impact. Journal of Personality and Social Psychology, 85(3), 541-553.

Hershey, D. A., and Mowen, J. C. (2000). Psychological determinants of financial preparedness for retirement. The Gerontologist, 40(6), 687-697.

Hitt, C.E., Trivitt, J.R., and Cheng, A. (2016). When you say nothing at all: The predictive power of student effort on surveys. Economics of Education Review, 52, 105-119

Hitt, C.E. (2015). Just filling in the bubbles: Using careless answer patterns on surveys as a proxy measure of noncognitive skills. EDRE Working Paper 2015-06. Fayetteville, AR: Department of Education Reform, University of Arkansas.

Huang, J. L., Curran, P.G., Keeney, J., Poposki, E. M. and DeShon R. P. (2012). Detecting and deterring insufficient effort responding to surveys. Journal of Business and Psychology, 27(1), 99-114.

Hurd, M. D., Duckworth, A., Rohwedder, S., and Weir, D. R. (2012). Personality Traits and Economic Preparation for Retirement. MRRC Working paper 2012-09. University of Michigan Retirement Research Center.

John, O. P., and Srivastava, S. (1999). The Big Five trait taxonomy: History, measurement, and theoretical perspectives. Handbook of personality: Theory and research, 2(1999), 102138.

Johnson, J. A. (2005). Ascertaining the validity of individual protocols from web-based personality inventories. Journal of Research in Personality, 39, 103-129. 
Krosnick, J. A., Narayan, S. and Smith, W. R. (1996). Satisficing in surveys: Initial evidence. New Directions for Evaluation, 70, 29-44.

Levitt, S. D., and List, J. A. (2007). What do laboratory experiments measuring social preferences reveal about the real world?. The Journal of Economic Perspectives, 21(2), 153-174.

Lipkus, I. M., Samsa, G. and Rimer, B. K. (2001). General performance on a numeracy scale among highly educated samples. Medical Decision Making, 21(1), 37-44.

Mather, N., and Jaffe, L. E. (2016). Woodcock-Johnson IV: Reports, recommendations, and strategies. In Jossey-Bass, Wiley: Hoboken, NJ.

Meade, A. W., and Craig S. B. (2012). Identifying careless responses survey data. Psychological Methods, 17(3), 437-455.

O'Connor, P. J., Sullivan, G. L., and Jones, W. H. (1982). An evaluation of the characteristics of response quality induced by follow-up survey methods. Advances in Consumer Research, 9(1), 257-259.

Parise, G., and Peijnenburg, K. (2017). Understanding the determinants of financial outcomes and choices: The role of noncognitive abilities. HEC Paris Research Paper No. FIN-20171193.

Poterba, J. M. (1996). Personal saving behavior and retirement income modeling: A research assessment. In E. A. Hanushek and N. L. Maritato (Eds.), Assessing knowledge of retirement behavior (pp. 123-148).Washington, DC: National Academy Press.

Toplak, M. E., West, R. F. and Stanovich. K. E. (2014). Assessing miserly information processing: An expansion of the cognitive reflection test. Thinking \& Reasoning, 20(2), 147-168. 
Tourangeau, R., and Yan, T. (2007). Sensitive questions in surveys. Psychological Bulletin, 133(5), 859-883.

West, M. R., Kraft, M. A., Finn, A. S., Martin, R., Duckworth, A. L., Gabrieli, C. F. O., and Gabrieli, J. D. E. (2016). Promise and paradox: Measuring students’ non-cognitive skills and the impact of schooling. Educational Evaluation and Policy Analysis, 38(1), 148170.

Zamarro, G., Cheng, A., Shakeel, M., and Hitt, C. (2016). Comparing and validating measures of non-cognitive skills: Findings from a nationally representative sample. EDRE Working Paper No. 2016-08. Fayetteville, AR: Department of Education Reform, University of Arkansas.

Zamarro, G., Hitt, C.E., and Mendez, I. (2016). When students don't care: Reexamining international differences in achievement and non-cognitive skills. EDRE Working Paper No. 2016-18. Fayetteville, AR: Department of Education Reform, University of Arkansas. 
Figure 1. Academic Diligence Task. Screenshots

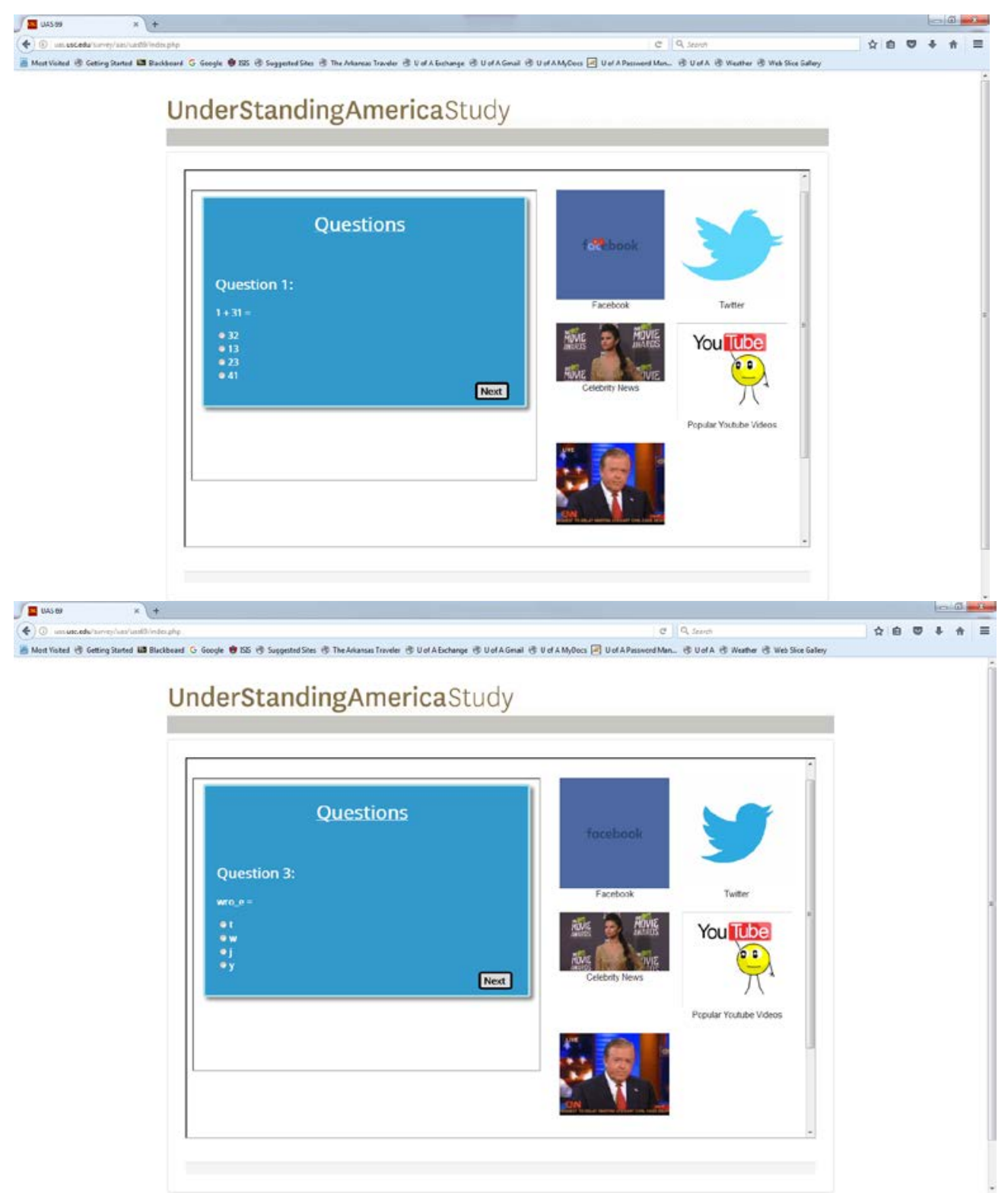


Figure 2. Academic Diligence Task. Percentage of Correct Responses

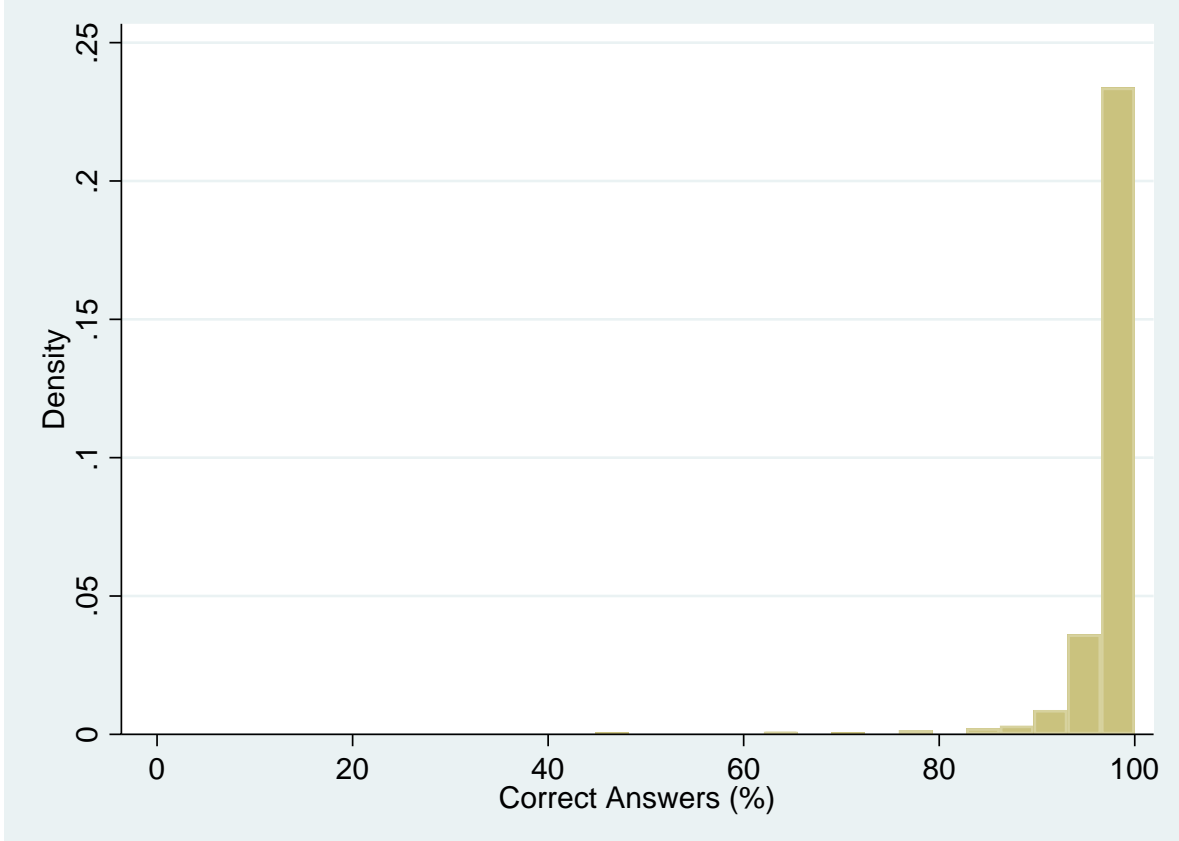

Figure 3. Academic Diligence Task. Time on Task

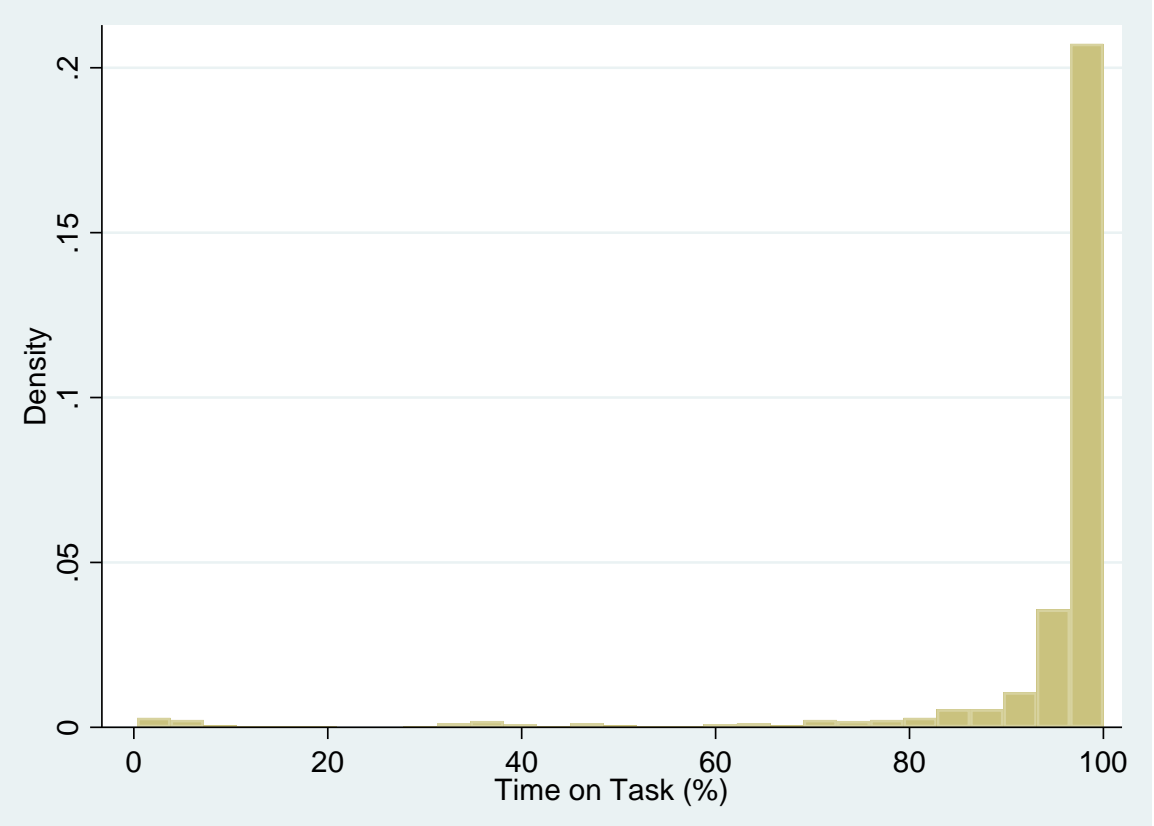


Table 1. Summary Statistics for Measures of Noncognitive skills

\begin{tabular}{lccccc}
\hline \multicolumn{1}{c}{ Measure } & Mean & St. Dev. & Min. & Max. & N. Obs \\
\hline 1. Grit & 3.58 & 0.60 & 1.37 & 5.00 & 4,906 \\
2. Conscientiousness & 4.05 & 0.62 & 1.00 & 5.00 & 5,224 \\
3. Agreeableness & 4.02 & 0.62 & 1.00 & 5.00 & 5,223 \\
4. Neuroticism & 2.64 & 0.82 & 1.00 & 5.00 & 5,222 \\
5. Extraversion & 3.35 & 0.79 & 1.00 & 5.00 & 5,218 \\
6. Openness & 3.61 & 0.63 & 1.00 & 5.00 & 5,218 \\
7. Item nonresponse & 0.08 & 0.02 & 0.01 & 0.48 & 5,021 \\
8. Careless Answers & 0.01 & 1.01 & -1.96 & 4.43 & 5,075 \\
9. Correct Answers & 0.97 & 0.06 & 0 & 1 & 901 \\
10. Time on Task & 92.90 & 17.15 & 0.34 & 100 & 904 \\
\hline
\end{tabular}

Note: Summary statistics presented using population weights. 
Table 2. Correlation Matrix of Noncognitive Traits Measures

\begin{tabular}{|c|c|c|c|c|c|c|c|c|}
\hline & 1 & 2 & 3 & 4 & 5 & 6 & 7 & 8 \\
\hline 1. Grit & - & & & & & & & \\
\hline 2. Conscientiousness & $0.50 * *$ & - & & & & & & \\
\hline 3. Agreeableness & $0.24 * *$ & $0.42 * *$ & - & & & & & \\
\hline 4. Neuroticism & $-0.33^{* *}$ & $-0.39 * *$ & $-0.42 * *$ & - & & & & \\
\hline 5. Extroversion & $0.18 * *$ & $0.24^{* *}$ & $0.21^{* *}$ & $-0.28 * *$ & - & & & \\
\hline 6. Openness & $0.14^{* *}$ & $0.23^{* *}$ & $0.23 * *$ & $-0.21 * *$ & $0.32 * *$ & - & & \\
\hline 7. Item nonresponse & $-0.05 * *$ & $-0.04^{* *}$ & $-0.04 * *$ & $0.02 \dagger$ & -0.01 & $-0.05 * *$ & - & \\
\hline 8. Careless Answers & $-0.16^{* *}$ & $-0.18 * *$ & $-0.10 * *$ & $0.27 * *$ & $-0.10 * *$ & $-0.03 *$ & $0.05 * *$ & - \\
\hline 9. Correct Answers & 0.06 & 0.04 & 0.03 & -0.01 & 0.02 & 0.01 & $-0.10^{* *}$ & $-0.10 * *$ \\
\hline 10. Time on Task & -0.006 & 0.01 & -0.0003 & -0.01 & 0.01 & 0.005 & 0.001 & -0.03 \\
\hline
\end{tabular}

Note: $\dagger \mathrm{p}<0.1 ;{ }^{*} \mathrm{p}<0.05 ;{ }^{* *} \mathrm{p}<0.01$. 
Table 3. Summary Statistics for Outcome Variables

\begin{tabular}{|c|c|c|c|c|}
\hline Measure & Mean & $\begin{array}{l}\text { Standard } \\
\text { Deviation }\end{array}$ & $\begin{array}{c}\text { Minimu } \\
\text { m }\end{array}$ & Maximum \\
\hline \multicolumn{5}{|l|}{ Financial Capability } \\
\hline Financial Literacy & 13.84 & 3.08 & 0 & 20 \\
\hline Perceived Fin. Liter. & 13.20 & 4.35 & 0 & 20 \\
\hline Tot. Val. Assets (10,000s) & 28.75 & 107.31 & -687.51 & 3607 \\
\hline \multicolumn{5}{|l|}{$\begin{array}{l}\text { Consumer Financial Well- } \\
\text { being }\end{array}$} \\
\hline Consumer Fin. Well. & 53.99 & 12.88 & 14 & 95 \\
\hline $\begin{array}{l}\text { Good or Excellent } \\
\text { Credit. }\end{array}$ & 0.49 & 0.50 & 0 & 1 \\
\hline \multicolumn{5}{|l|}{ Retirement Preparation } \\
\hline Prepared retirement & 0.22 & 0.42 & 0 & 1 \\
\hline Thought of retirement & 0.13 & 0.34 & 0 & 1 \\
\hline \multicolumn{5}{|c|}{ Note: Sample sizes range from 3,104 to 5,949. Summary statistics use population } \\
\hline Measure & Mean & $\begin{array}{l}\text { Standard } \\
\text { Deviation }\end{array}$ & $\underset{\mathbf{m}}{\text { Minimu }}$ & Maximum \\
\hline Age & 47.33 & 16.78 & 18 & 98 \\
\hline Female & 0.52 & 0.50 & 0 & 1 \\
\hline Black & 0.12 & 0.32 & 0 & 1 \\
\hline Hispanic & 0.001 & 0.025 & 0 & 1 \\
\hline Other Race & 0.24 & 0.43 & 0 & 1 \\
\hline Born in USA & 0.91 & 0.29 & 0 & 1 \\
\hline West & 0.18 & 0.39 & 0 & 1 \\
\hline Midwest & 0.08 & 0.28 & 0 & 1 \\
\hline Northeast & 0.11 & 0.32 & 0 & 1 \\
\hline South & 0.27 & 0.45 & 0 & 1 \\
\hline Working & 0.61 & 0.41 & 0 & 1 \\
\hline Retired & 0.19 & 0.31 & 0 & 1 \\
\hline High School Degree & 0.50 & 0.50 & 0 & 1 \\
\hline College & 0.40 & 0.49 & 0 & 1 \\
\hline $\begin{array}{l}\text { Married/ Living } \\
\text { Togeth }\end{array}$ & 0.57 & 0.49 & 0 & 1 \\
\hline $\begin{array}{l}\text { Cognitive Ability- } \\
\text { Factor }\end{array}$ & -0.10 & 1.00 & -3.02 & 2.64 \\
\hline
\end{tabular}

Note: Summary statistics use population weights 
Table 5. A. Financial Capability and Self-Reported Measures of Noncognitive skills (OLS estimates)

\begin{tabular}{|c|c|c|c|c|c|c|}
\hline Variables & $\begin{array}{c}\text { (1) } \\
\text { Fin. Lit }\end{array}$ & $\begin{array}{c}\text { (2) } \\
\text { Fin. Lit }\end{array}$ & $\begin{array}{c}\text { (3) } \\
\text { Perc. Fin. } \\
\text { lit }\end{array}$ & $\begin{array}{l}\text { (4) } \\
\text { Perc. Fin. } \\
\quad \text { lit }\end{array}$ & $\begin{array}{c}\text { (5) } \\
\text { Total } \\
\text { Assets } \\
\end{array}$ & $\begin{array}{c}\text { (6) } \\
\text { Total } \\
\text { Assets } \\
\end{array}$ \\
\hline Cognitive Ability & $\begin{array}{c}1.456 * * * \\
(0.053)\end{array}$ & $\begin{array}{c}1.452 * * * \\
(0.056)\end{array}$ & $\begin{array}{c}1.189 * * * \\
(0.097)\end{array}$ & $\begin{array}{c}1.202 * * * \\
(0.095)\end{array}$ & $\begin{array}{c}6.801 * * * \\
(2.478)\end{array}$ & $\begin{array}{c}6.954 * * * \\
(2.678)\end{array}$ \\
\hline Conscientiousness & $\begin{array}{c}-0.069 \\
(0.080)\end{array}$ & & $\begin{array}{c}0.335 * * \\
(0.149)\end{array}$ & & $\begin{array}{c}4.230 \\
(4.603)\end{array}$ & \\
\hline Agreeableness & $\begin{array}{c}0.131 \\
(0.085)\end{array}$ & & $\begin{array}{c}-0.343^{* *} \\
(0.169)\end{array}$ & & $\begin{array}{c}-1.249 \\
(4.013)\end{array}$ & \\
\hline Neuroticism & $\begin{array}{c}0.037 \\
(0.059)\end{array}$ & & $\begin{array}{c}-0.349 * * * \\
(0.115)\end{array}$ & & $\begin{array}{l}-4.497 \\
(3.474)\end{array}$ & \\
\hline Extraversion & $\begin{array}{c}-0.065 \\
(0.058)\end{array}$ & & $\begin{array}{c}0.248 * * \\
(0.107)\end{array}$ & & $\begin{array}{c}2.454 \\
(2.510)\end{array}$ & \\
\hline Openness & $\begin{array}{c}0.198 * * * \\
(0.069)\end{array}$ & & $\begin{array}{c}0.116 \\
(0.138)\end{array}$ & & $\begin{array}{c}2.732 \\
(2.751)\end{array}$ & \\
\hline Grit & & $\begin{array}{c}-0.024 \\
(0.072)\end{array}$ & & $\begin{array}{c}0.434 * * * \\
(0.135)\end{array}$ & & $\begin{array}{c}4.904 \\
(3.993)\end{array}$ \\
\hline Observations & 4,381 & 4,048 & 4,037 & 3,741 & 2,846 & 2,799 \\
\hline Adjusted R-squared & 0.469 & 0.459 & 0.271 & 0.274 & 0.0446 & 0.0432 \\
\hline
\end{tabular}

Note: Demographic variables, educational attainment levels, and employment and marital status included as controls. Standard errors in parentheses; *** $\mathrm{p}<0.01,{ }^{* *} \mathrm{p}<0.05$, * $\mathrm{p}<0.1$. 
Table 5. B. Financial Capability and Survey Effort Measures of Noncognitive skills (OLS estimates)

\begin{tabular}{|c|c|c|c|c|c|c|}
\hline Variables & $\begin{array}{c}\text { (1) } \\
\text { Fin. Lit }\end{array}$ & $\begin{array}{c}\text { (2) } \\
\text { Fin. Lit }\end{array}$ & $\begin{array}{c}\text { (3) } \\
\text { Perc. Fin. } \\
\text { lit }\end{array}$ & $\begin{array}{l}\text { (4) } \\
\text { Perc. Fin. } \\
\quad \text { lit }\end{array}$ & $\begin{array}{c}\text { (5) } \\
\text { Total } \\
\text { Assets }\end{array}$ & $\begin{array}{c}\text { (6) } \\
\text { Total } \\
\text { Assets } \\
\end{array}$ \\
\hline Cognitive Ability & $\begin{array}{c}1.459 * * * \\
(0.053)\end{array}$ & $\begin{array}{c}1.463 * * * \\
(0.053)\end{array}$ & $\begin{array}{c}1.175^{* * *} \\
(0.094)\end{array}$ & $\begin{array}{c}1.152 * * * \\
(0.094)\end{array}$ & $\begin{array}{c}7.120 * * * \\
(2.602)\end{array}$ & $\begin{array}{c}6.073 * * \\
(2.513)\end{array}$ \\
\hline Item Nonresponse & $\begin{array}{c}-6.671 * * * \\
(2.341)\end{array}$ & & $\begin{array}{l}-7.705 \\
(7.449)\end{array}$ & & $\begin{array}{c}164.874 * * * \\
(54.377)\end{array}$ & \\
\hline Careless Answering & & $\begin{array}{c}-0.094 * * \\
(0.045)\end{array}$ & & $\begin{array}{c}-0.308^{* * *} \\
(0.093) \\
\end{array}$ & & $\begin{array}{c}-3.628 * * \\
(1.429)\end{array}$ \\
\hline Observations & 4,395 & 4,395 & 4,046 & 4,046 & 2,856 & 2,856 \\
\hline Adjusted R-squared & 0.469 & 0.469 & 0.265 & 0.265 & 0.049 & 0.044 \\
\hline
\end{tabular}

Note: Demographic variables, educational attainment levels, and employment and marital status included as controls. Standard errors in parentheses; *** $\mathrm{p}<0.01, * * \mathrm{p}<0.05$, * $\mathrm{p}<0.1$. 
Table 6. A. Consumer Financial Well-being and Self-Reported Measures of Noncognitive skills (OLS estimates)

\begin{tabular}{|c|c|c|c|c|}
\hline Variables & $\begin{array}{c}(1) \\
\text { Fin. } \\
\text { Well. }\end{array}$ & $\begin{array}{c}(2) \\
\text { Fin. } \\
\text { Well. }\end{array}$ & $\begin{array}{c}\text { (3) } \\
\text { Good/ Excell. } \\
\text { Credit }\end{array}$ & $\begin{array}{c}(4) \\
\text { Good/ Excell. } \\
\text { Credit }\end{array}$ \\
\hline Cognitive Ability & $\begin{array}{c}1.803 * * * \\
(0.263)\end{array}$ & $\begin{array}{c}1.814^{* * *} \\
(0.274)\end{array}$ & $\begin{array}{c}0.076 * * * \\
(0.012)\end{array}$ & $\begin{array}{c}0.074^{* * *} \\
(0.011)\end{array}$ \\
\hline Conscientiousness & $\begin{array}{c}2.636 * * * \\
(0.402)\end{array}$ & & $\begin{array}{c}0.066 * * * \\
(0.018)\end{array}$ & \\
\hline Agreeableness & $\begin{array}{c}-0.543 \\
(0.387)\end{array}$ & & $\begin{array}{c}-0.030 * \\
(0.018)\end{array}$ & \\
\hline Neuroticism & $\begin{array}{c}-2.391 * * * \\
(0.318)\end{array}$ & & $\begin{array}{c}-0.011 \\
(0.013)\end{array}$ & \\
\hline Extraversion & $\begin{array}{c}0.622 * * \\
(0.295)\end{array}$ & & $\begin{array}{c}0.010 \\
(0.013)\end{array}$ & \\
\hline Openness & $\begin{array}{l}-0.593 \\
(0.371)\end{array}$ & & $\begin{array}{c}-0.040 * * \\
(0.016)\end{array}$ & \\
\hline Grit & & $\begin{array}{c}3.834 * * * \\
(0.394)\end{array}$ & & $\begin{array}{c}0.021 \\
(0.017)\end{array}$ \\
\hline Observations & 4,324 & 4,021 & 3,467 & 3,415 \\
\hline Adjusted R-squared & 0.268 & 0.258 & 0.232 & 0.226 \\
\hline
\end{tabular}

Note: Demographic variables, educational attainment levels, and employment and marital status included as controls. Standard errors in parentheses; *** $\mathrm{p}<0.01,{ }^{* *} \mathrm{p}<0.05,{ }^{*} \mathrm{p}<0.1$. 
Table 6. B. Consumer Financial Well-being and Survey-Effort Measures of Noncognitive skills (OLS estimates)

\begin{tabular}{lcccc}
\hline & $\mathbf{( 1 )}$ & $\mathbf{( 2 )}$ & $\begin{array}{c}(\mathbf{3}) \\
\text { Good/ Excell. } \\
\text { Credit }\end{array}$ & $\begin{array}{c}\text { (4) } \\
\text { Good/ Excell. } \\
\text { Credit }\end{array}$ \\
\hline Cognitive Ability & Fin. Well. & Fin. Well. & $0.074^{* * *}$ & $0.067^{* * *}$ \\
& $1.576^{* * *}$ & $1.376^{* * *}$ & $(0.011)$ & $(0.011)$ \\
Item Nonresponse & $(0.256)$ & $(0.260)$ & 0.315 & \\
& $-71.306^{* * *}$ & & $(0.534)$ & \\
Careless Answering & $(18.808)$ & & & $-0.051^{* * *}$ \\
& & $-2.850^{* * *}$ & & $(0.010)$ \\
\hline Observations & & $(0.253)$ & 3,482 & 3,482 \\
Adjusted R-squared & 0.229 & 0.330 & 0.227 & 0.236 \\
\hline
\end{tabular}

Note: Demographic variables, educational attainment levels, and employment and marital status included as controls. Standard errors in parentheses; *** $\mathrm{p}<0.01, * * \mathrm{p}<0.05, * \mathrm{p}<0.1$. 
Table 7. A. Retirement Preparation and Self-Reported Measures of Noncognitive skills (OLS estimates)

\begin{tabular}{|c|c|c|c|c|}
\hline Variables & $\begin{array}{c}(1) \\
\text { Prep. } \\
\text { Retire. }\end{array}$ & $\begin{array}{c}(2) \\
\text { Prep. } \\
\text { Retire. }\end{array}$ & $\begin{array}{c}\text { (3) } \\
\text { Thought } \\
\text { Ret. }\end{array}$ & $\begin{array}{c}\text { (4) } \\
\text { Thought } \\
\text { Ret. }\end{array}$ \\
\hline Cognitive Ability & $\begin{array}{c}0.020 * * \\
(0.009)\end{array}$ & $\begin{array}{c}0.021^{* *} \\
(0.010)\end{array}$ & $\begin{array}{c}0.037 * * * \\
(0.007)\end{array}$ & $\begin{array}{c}0.042 * * * \\
(0.008)\end{array}$ \\
\hline Conscientiousness & $\begin{array}{c}0.058^{* * *} \\
(0.013)\end{array}$ & & $\begin{array}{c}0.034^{* * *} \\
(0.011)\end{array}$ & \\
\hline Agreeableness & $\begin{array}{c}-0.032^{* *} \\
(0.013)\end{array}$ & & $\begin{array}{c}0.005 \\
(0.011)\end{array}$ & \\
\hline Neuroticism & $\begin{array}{c}-0.021^{* *} \\
(0.010)\end{array}$ & & $\begin{array}{c}0.011 \\
(0.009)\end{array}$ & \\
\hline Extraversion & $\begin{array}{c}0.026^{* *} \\
(0.011)\end{array}$ & & $\begin{array}{l}0.015^{*} \\
(0.008)\end{array}$ & \\
\hline Openness & $\begin{array}{l}-0.012 \\
(0.013)\end{array}$ & & $\begin{array}{c}0.008 \\
(0.011)\end{array}$ & \\
\hline Grit & & $\begin{array}{c}0.032 * * \\
(0.014)\end{array}$ & & $\begin{array}{c}0.033^{* * *} \\
(0.011) \\
\end{array}$ \\
\hline Observations & 4,566 & 4,062 & 4,566 & 4,062 \\
\hline Adjusted R-squared & 0.195 & 0.183 & 0.143 & 0.142 \\
\hline
\end{tabular}

Note: Demographic variables, educational attainment levels, employment, and marital status included as controls. Standard errors in parentheses; ${ }^{* *} \mathrm{p}<0.01,{ }^{* *} \mathrm{p}<0.05,{ }^{*} \mathrm{p}<0.1$. 
Table 7. B. Retirement Preparation and Survey-Effort Measures of Noncognitive skills (OLS estimates)

\begin{tabular}{lcccc}
\hline & $\begin{array}{c}\mathbf{( 1 )} \\
\text { Prep. } \\
\text { Retire. }\end{array}$ & $\begin{array}{c}\text { (2) } \\
\text { Prep. } \\
\text { Retire. }\end{array}$ & $\begin{array}{c}\text { (3) } \\
\text { Thought } \\
\text { Ret. }\end{array}$ & $\begin{array}{c}\text { (4) } \\
\text { Thought } \\
\text { Ret. }\end{array}$ \\
\hline Cognitive Ability & $0.019^{* *}$ & 0.011 & $0.035^{* * *}$ & $0.034^{* * *}$ \\
& $(0.009)$ & $(0.009)$ & $(0.007)$ & $(0.007)$ \\
Item Nonresponse & 0.691 & & -0.180 & \\
& $(0.476)$ & & $(0.240)$ & \\
Careless Answering & & $-0.045^{* * *}$ & & $-0.014^{* *}$ \\
& & $(0.008)$ & & $(0.006)$ \\
\hline Observations & 4,579 & 4,512 & 4,579 & 4,512 \\
Adjusted R-squared & 0.185 & 0.193 & 0.139 & 0.140 \\
\hline
\end{tabular}

Note: Demographic variables, educational attainment levels, employment, and marital status included as controls. Standard errors in parentheses; ${ }^{* *} \mathrm{p}<0.01,{ }^{* *} \mathrm{p}<0.05,{ }^{*} \mathrm{p}<0.1$. 